Original Research

\title{
Adductor squeeze test and groin injuries in elite football players: A prospective study
}

\author{
V. Moreno-Pérez ${ }^{\text {a, }}{ }^{*}$, B. Travassos ${ }^{\text {b }}$, A. Calado ${ }^{\text {c }}$, O. Gonzalo-Skok ${ }^{\mathrm{d}}$, J. Del Coso ${ }^{\mathrm{e}}$, \\ A. Mendez-Villanueva ${ }^{\mathrm{f}}$ \\ a Sports Research Centre, Miguel Hernandez University of Elche, Avda. de La Universidad s/n, 03202, Elche, Alicante, Spain \\ ${ }^{\mathrm{b}}$ Departamento de Ciências do Desporto, Universidade da Beira Interior, Convento de Sto. António. 6201-001, Covilhã, Portugal \\ ${ }^{\mathrm{c}}$ Rio Ave Rendimento, Rio Ave FC, Rua Sancho I, Estadio do Rio Ave, 4489-876, Vila do Conde, Portugal \\ d Faculty of Health Sciences, University of San Jorge of Zaragoza, Villanueva de Gállego, 50830, Zaragoza, Spain \\ exercise Physiology Laboratory, Camilo José Cela University, Sport Sciences Institute Castillo de Alarcón, 49, Villafranca del Castillo, None, 28692, Spain \\ ${ }^{\mathrm{f}}$ Qatar Football Association, Doha, Qatar
}

\section{A R T I C L E I N F O}

\section{Article history:}

Received 12 September 2018

Received in revised form

28 February 2019

Accepted 1 March 2019

\section{Keywords:}

Adductor

Soccer

Team-sport

Injury rate

Risk factor

\begin{abstract}
A B S T R A C T
Objective: To examining the relationship between hip adductor strength and groin injury incidence during the competitive season of professional football teams.

Design: Prospective Cohort study.

Setting: Controlled laboratory environment.

Participants: Seventy-one players volunteered to participate.

Main outcome measures: In the pre-season, maximal hip adductor strength was measured by means of the isometric adductor squeeze test. Hip adductor strength, normalized by body mass, was compared between players who suffered a groin injury $(n=18)$ vs uninjured players $(n=53)$. Risk ratios $(R R)$ were used to evaluate the likelihood of players to suffer this type of injury.

Results: Most of the reported groin injuries occurred during competitive matches (5.5 per 1000 match hours). Maximal isometric hip adductor strength was lower in the groin-injured group compared with their uninjured counterparts $(429.8 \pm 100$ vs $564 \pm 58.7 \mathrm{~N}, \mathrm{~d}=-1.58$ and $5.40 \pm 1.27 \mathrm{vs} 7.71 \pm 0.89 \mathrm{~N} / \mathrm{kg}$, $\mathrm{d}=-1.88$, respectively). Results revealed that values of maximal isometric adductor strength lower than $465.33 \mathrm{~N}$ increased the probability to suffer a groin injury by $72 \%$. Furthermore, values of force relative to body mass lower than $6.971 \mathrm{~N} / \mathrm{kg}$ increased the probability to suffer a groin injury by $83 \%$.

Conclusion: The assessment of Hip adductor strength, in addition to other measurements, might help practitioners to determine the probability of suffering an overuse groin injuries in elite football players.
\end{abstract}

(ㄷ) 2019 Elsevier Ltd. All rights reserved.

\section{Introduction}

Football (soccer) is an intermittent team sport with high physical, technical, and tactical demands (Arnason et al., 2004). Associated with the high physical demands of this team sport, previous studies have reported a relatively high injury incidence in football players, with 20-35 injuries per 1000 h of play (Waldén, Hägglund, \& Ekstrand, 2005; Dvorak, Junge, Grimm, \& Kirkendall, 2007;

\footnotetext{
* Corresponding author.

E-mail addresses: vmoreno@goumh.es (V. Moreno-Pérez), brunotravassos@ hotmail.com (B. Travassos), acalado1981@hotmail.com (A. Calado), oligons@ hotmail.com (O. Gonzalo-Skok), jdelcoso@ucjc.edu (J. Del Coso), amendezvillanueva@yahoo.com (A. Mendez-Villanueva).
}

Ekstrand, Hägglund, \& Ekstrand, 2011. Specifically, groin injuries represent one of the most common injuries in elite football with values ranging from $14 \%$ to $18 \%$ of the total number of injuries (Hägglund, Waldén, \& Ekstrand, 2009; Werner, Hagglund, Walden, \& Ekstrand, 2009), although these values can be lower in amateur football (Herrero, Salinero, \& Del Coso, 2014). In addition, a recent study of male football players found that groin injuries accounted for $18 \%$ of all time-loss injuries (Mosler et al., 2018a). Furthermore, the available literature indicates that nearly $18 \%$ of overuse groin injuries will recur within 2 years, while $11 \%$ will recur in less than 2 months (Mosler et al., 2018a). Long-term symptoms in groin injuries are mainly the result of repetitive and sudden changes of direction and/or sprinting during football play, and during kicking actions during practices and competition (Machotka, Kumar, \& 
Perraton, 2009; Delahunt, Kennelly, McEntee, Coughlan, \& Green, 2011) while the incidence of acute groin injuries is lower in football (Hölmich, Thorborg, Dehlendorff, Krogsgaard, \& Gluud, 2014). In order to implement preventive measures to minimize the risk of injury incidence, the identification of the risk factors associated with the occurrence of groin injury is crucial (Whittaker, Small, Maffey, \& Emery, 2015).

Several non-modifiable internal risk factors such as previous injury (Engebretsen, Myklebust, Holme, \& Engebretsen, 2010; Mosler et al., 2018b), older age (Arnason et al., 2004; O'Connor, 2004), higher level of competition (Tyler, Nicholas, Campbell, \& McHugh, 2001), and modifiable risk factors such as decreased range of hip abduction and internal rotation motion (Arnason et al., 2004; Ibrahim, Murrell, \& Knapman, 2007; Tak et al., 2016) have been related to an increased likelihood of suffering a groin injury in football players. In addition, isometric adductor muscle weakness and/or a lower ratio between adductor/abductor muscle strength have also been reported as possible physical risk factors for groin injury in football (Engebretsen, Myklebust, Holme, Engebretsen, \& Bahr, 2010; Esteve et al., 2018) and other sports (Tyler et al., 2001; Crow et al., 2010; Ryan, DeBurca, \& Mc Creesh, 2014; Moreno-Pérez, Lopez-Valenciano, Barbado, Moreside, Elvira J, \& Vera-Garcia, 2017). The combination of adductor muscle weakness and previous groin injury could further increase the probability of developing groin pain (Engebretsen et al., 2010; Esteve et al., 2018; Mosler et al., 2018b). Esteve et al. (2018) in a cross-sectional study of amateur football players identified that players who suffered from past-season groin pain for more than 6 weeks showed 13\%-19\% lower isometric adductor strength than the control players. This adds to the hypothesis that low values of isometric adductor strength might increase the risk of having a groin injury. Despite this evidence, few studies have examined the role that adductor strength plays in the aetiology of a groin injury in football and this warrants further prospective investigation (Mohammad, Abdelraouf, Elhafez, Abdel-Aziem, \& Nassif, 2014).

Even though several methods have been described to assess adductor muscle strength (Emery \& Meeuwisse, 2001; Thorborg et al., 2011; Tyler et al., 2001), the popularity of the adductor squeeze test has increased in several sports like football (Hanna, Fulcher, Elley, \& Moyes, 2010; Mosler et al., 2017; Esteve et al., 2018 and rugby (Coughlan, Delahunt, Caulfield, Forde, \& Green, 2014) due to its simplicity, low-cost, good reliability and validity (Delahunt et al., 2011). In addition, this test is a popular screening tool used to identify changes in adductor strength in order to minimize the groin injury risk in several sports (Roe et al., 2016).

All this previous information suggests that reduced hip adductor strength in football players might be associated with a higher probability to suffer a groin injury. Only two recent studies have analysed pre-season strength in the adductor squeeze test to identify elite football players at risk of developing groin injury (Bakken et al., 2018; Mosler et al., 2018b) while their results are inconclusive. Therefore, the aim of the present study was to analyse the association between hip adductor strength, assessed with the adductor squeeze test, and groin injury incidence during a competitive season in elite football players.

\section{Methods}

\subsection{Participants}

From an initial sample of ninety healthy football players, seventy-one took part in this prospective study. The participants were recruited from a professional team of the Portuguese First Division League (Primeira Liga: $\mathrm{n}=35$; age $=24.8 \pm 4.2$ years; body mass $=79.9 \pm 5.8 \mathrm{~kg}$; height $=1.82 \pm 5.52 \mathrm{~m}$ ) and from the U-19 team of the same football club (First National League: $\mathrm{n}=36$; age $=17.4 \pm 0.6 \quad$ years; $\quad$ body $\quad$ mass $=70.7 \pm 7.2 \mathrm{~kg}$; height $=175.7 \pm 7.6 \mathrm{~m}$ ). Fifty-four participants were right-leg dominant and 17 were left-leg dominant. At the beginning of each season the players belonging to the respective squads were evaluated and injuries were reported. The exclusion criteria were: a) a history of hip and groin orthopaedic problems within the previous three months to the onset of the investigation (three senior players); b) inability to undertake testing due to other injuries (three senior players and one U-19 player); c) transfer to other club during the season (nine senior players and three U-19 players). A written informed consent was obtained from each participant, their parents (U-19 players) and the club, prior to testing. The experimental procedures used in this study were in accordance with the Declaration of Helsinki and the ethical standards of the local committee.

\subsection{Data collection}

Physical variables were obtained during the 2015-2016 and 2016-2017 pre-seasons always before football training. In the 2015-2016 season, data were obtained from 14 professional players and 16 U-19 players; in the 2016-2017 season, data were obtained from 21 professional players and 20 U-19 players. Participants performed a warm-up consisting in 5-min of jogging (light intensity [10-12 points of the Bog-scale]) and an 8-min protocol of standardised static stretching exercises in leg and trunk muscles (Cejudo, Sainz de Baranda, Ayala, \& Santonja, 2015). Specifically, participants performed 2 repetitions of 7 different unassisted and static stretching exercises, holding the stretch position for $30 \mathrm{~s}$. Thereafter, participants performed the hip adductor strength test, as previously described (Delahunt et al., 2011). One week before testing, all football players were familiarized with the procedures to reduce the influence of the learning effect. The measurements of the hip adductor strength were performed by the same two experienced members of the team's medical staff with previous skills in the tests employed in this investigation. Examiner 1 (>12 years' experience) conducted all measurements with the dynamometer while examiner 2 (5 years' experience) ensured a proper and reliable testing position to assure that all participants were tested in the same conditions.

During the competitive season, all injuries were meticulously diagnosed and recorded by the medical staff of the football team, following the recommendations of the Medical Assessment and Research Centre (F-MARC), sponsored by the Federation Internationale de Football Association (Fuller et al., 2006). In addition, the time devoted to football training and the match play were individually obtained by the physical trainer of each football team to calculate time of exposure for training and match.

\subsection{Measurements}

\subsubsection{Adductor squeeze strength test}

For the measurement of maximal isometric hip adductor strength, each participant laid supine on a bench and, as explained elsewhere (Delahunt et al., 2011). Hips were positioned in a $45^{\circ}$ flexion with knees flexed to $90^{\circ}$ and hips in neutral rotation. The squeeze test was quantified using a handheld dynamometer (Smart Groin Trainer, Neuro Excellence, Portugal). The measurement of maximal isometric hip adductor strength with this same portable dynamometer is reliable and with low values of error $($ ICC $=0.94$ (0.86-0.97); minimal detectable change $(M D C)=25.3 \mathrm{~N} ; \%$ $\mathrm{MDC}=5.7 \%$ (Mesquita et al., 2018); ). The dynamometer was placed between the knees (Fig. 1), specifically it was located at the most prominent point of the medial femoral condyles. Players were 


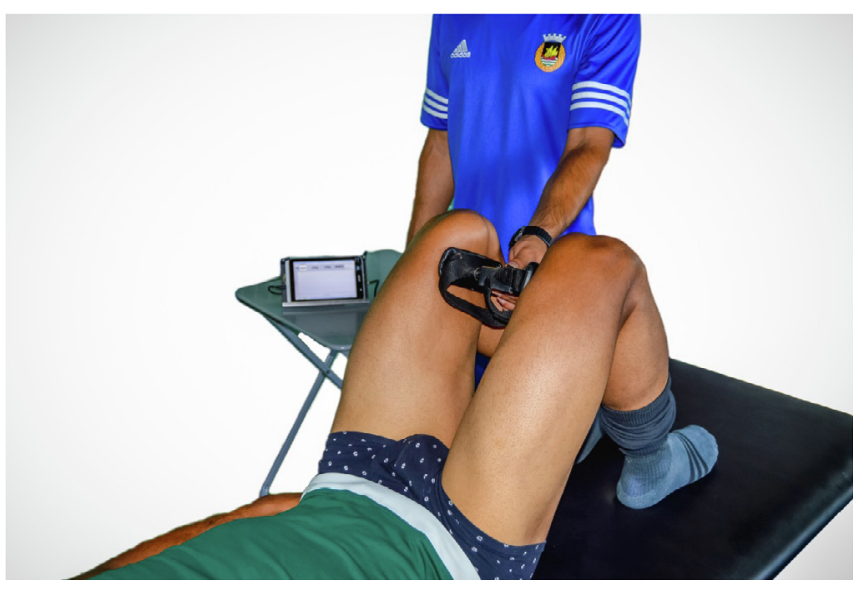

Fig. 1. Example of a measurement with the adductor $45^{\circ}$ squeeze test.

instructed to squeeze the cuff as hard as possible for 3 maximum contractions and held for $5 \mathrm{~s}$ with $3 \mathrm{~min}$ of passive recovery between contractions. The maximal pressure (squeeze) value displayed on the dynamometer dial was recorded during each of the three test trials. The best of the three trials was used for analysis.

\subsubsection{Questionnaire}

At the time of the hip adductor strength measurement, each participant's height and body mass were documented, as well as age, lower leg dominant side and a report of previous injuries (see Table 1). Any injury case included in the data analysis was defined as "any physical complaint sustained by a player that results from a football match or training, irrespective of the need for the medical attention or time loss from football activities" (Fuller et al., 2006). A groin injury was referred to any physical symptom located in the groin area (i.e., contact injuries were not included) which prevented a player from taking full part in training and match play activities to remaining for a period longer than $24 \mathrm{~h}$ (starting at the midnight of the day of the injury [Murphy Gissane, \& Blake, 2012; Murphy, O'Malley E, Gissane C, \& Blake, 2012];). Injury severity was defined as the number of days that have elapsed from the date of injury to the date of the player's return to full participation in team (Fuller et al., 2006). The following classification was used to describe injury severity: "minimal, 1-3 days; mild, 4-7 days; moderate, $8-28$ days, and severe $>28$ days".

\subsection{Data analysis}

Force (N) and force relative to players' body mass values $(\mathrm{N} / \mathrm{kg})$ were used to individually assess maximal hip isometric adductor strength. Force relative to body mass was obtained through the calculation of the ratio of hip isometric adductor strength in relation to body mass of each player.

\subsection{Statistical analysis}

A descriptive analysis was performed using mean and standard deviations. Normality of the data distribution was verified using the Kolmogorov-Smirnov test. Groin injury incidence for the whole group of players was calculated as the number of groin injuries per $1000 \mathrm{~h}$ of match play and training. Groin-injured and uninjured players were compared via standardised mean differences, computed with pooled variance and respective $90 \%$ confidence intervals $(\mathrm{CI})$. Thresholds for effect sizes (ES) were 0.2, trivial; 0.6, small; 1.2 , moderate; 2.0 , large and $>2.0$, very large (Hopkins,
Marshall, Batterham, \& Hanin, 2009). The probability of differences was reported with $90 \%$ confidence limits (CL). Magnitudes of clear effects were considered as the following scale: $>5 \%$, unclear; 25-75\%, possibly; 75\%-95\%, likely; $95 \%-99 \%$, very likely; $>99 \%$, most likely (Hopkins et al., 2009). In addition, binary logistic regression was used to assess the relationship between maximal isometric adductor strength, force relative to body mass and injury risk. The dependent variable was groin injury. The Odds Ratio (OR) and their 95\% confidence intervals (CI), and the correspondent probabilities were determined. The threshold with the highest sensitivity and 1-specificity for maximal isometric adductor strength and force relative to body mass values was calculated using receiving operating characteristic (ROC) curves (Swets, 1988). All the statistical analyses were performed using IBM SPSS statistics for Windows (V22.0, Armonk, NY: IBM. Corp.) and the significance level was set at $\mathrm{p}<0.05$.

\section{Results}

Characteristics of the study participants are outlined in Table 1. Substantial differences were found in age, body mass, played games, time played and training time between groin-injured and uninjured players (Table 1). From the whole sample, fifty-three players (74.6\%) did not suffer groin injuries during the competitive season, and the remaining (25.3\% of players assessed) sustained 18 groin injuries in different players (12 adductor tendinopathies, 4 osteitis-pubis, and 2 femoral-acetabular impingement) during the same period. The number of groin injuries represented $10.5 \%$ of the total number of injuries. Specifically, $7 \%$ and $13.5 \%$ of all injuries that occurred during the first season and second season. In terms of severity, 10 were moderate injuries ( $8-28$ days) and 8 severe ( $>28$ days). The total groin injury incidence rate was 5.5 injuries per $1000 \mathrm{~h}$ played for matches and 0.3 per $1000 \mathrm{~h}$ for training sessions. There was significant difference between match-related and training-related groin injuries (5.2; 95\% CL 3.82 to 6.80 ).

Very large effect sizes were observed in maximal isometric hip adductor strength when comparing groin-injured and uninjured players $(429.8 \pm 100$ vs $564 \pm 58.7 \mathrm{~N}, d=-1.58 ; 90 \%$ CL -2.08 to -1.07 ; Fig. 2). Similar results were found for the force relative to body mass $(5.40 \pm 1.27$ vs $7.71 \pm 0.89 \mathrm{~N} / \mathrm{kg}, d=-1.88 ; 90 \% \mathrm{CL}-2.37$ to -1.39 ; Fig. 2).

The results from the binary logistic regression analysis showed a significant model for maximal isometric adductor strength $\left(\mathrm{X}^{2}=6.319 ; \mathrm{p}=0.12 ; \mathrm{R}^{2}=0.126\right)$ and force relative to body mass $\left(\mathrm{X}^{2}=41.613 ; \mathrm{p}<0.001 ; \mathrm{R}^{2}=0.654\right)$ (Table 2$)$. Force relative to body mass $(\mathrm{OR}=6.8$ (2.699-17.129) revealed highest effectiveness on predicting groin-injuries in football players than maximal isometric hip adductor strength $(\mathrm{OR}=1.005$ (1.001-1.009). That is, the increase in $1 \mathrm{~N}$ in maximal isometric adductor strength decreases the chance to suffer a groin injury in 1.005 , while the increase $1 \mathrm{~N} / \mathrm{kg}$ in force relative to body mass decreases the chance to suffer a groin injury in 6.8 times.

The ROC curve analysis identified the threshold for the maximal isometric adductor strength as $465.33 \mathrm{~N}$, with maximal sensitivity (0.887) and 1-specificity (0.278) between injured and non-injured players (C-statistic of $0.816,95 \%$ CI 0.697 to 0.935 and, $\mathrm{p}<0.001$ ). Based on the results from binary logistic regression analysis, a threshold of $465.33 \mathrm{~N}$ correspond to a probability to not suffer a groin injury of $72 \%$. The ROC curve analysis identified the threshold for the force relative to body mass as $6.971 \mathrm{~N} / \mathrm{kg}$, with maximal sensitivity (0.811) and 1-specificity (0.167) between injured and non-injured players (C-statistic of $0.936,95 \% \mathrm{CI} 0.80$ to 0.993 and, $\mathrm{p}<0.001$ ). Based on the results from binary logistic regression analysis, a threshold of $6.971 \%$ correspond to a probability to not 
Table 1

Descriptive characteristics of the football players who suffered a groin injury during the study or remained uninjured in this location during the competitive season.

\begin{tabular}{|c|c|c|c|c|c|}
\hline & All & Uninjured $(\mathrm{n}=53)$ & Groin-injured $(\mathrm{n}=18)$ & Cohen's $d(90 \% \mathrm{CL})$ & \\
\hline Age (years) & $22.0 \pm 4.2$ & $20.2 \pm 4.7$ & $23.5 \pm 3.7$ & $0.75(0.32-1.78)$ & very likely $\uparrow$ \\
\hline Body mass (kg) & $76.9 \pm 7.5$ & $73.7 \pm 7.6$ & $79.9 \pm 7.1$ & $0.83(0.39-1.27)$ & very likely $\uparrow$ \\
\hline Body height (m) & $1.79 \pm 0.06$ & $1.77 \pm 0.07$ & $1.82 \pm 0.06$ & $0.69(0.27-1.11)$ & very likely $\uparrow$ \\
\hline Matches played (\#) & $32 \pm 8$ & $44 \pm 10$ & $21 \pm 6$ & $-2.51(-3.06$ to $-1,95)$ & most likely $\downarrow$ \\
\hline Match exposure (min) & $2715 \pm 726$ & $3960 \pm 891$ & $1471 \pm 561$ & $-3.03(-3.63$ to -2.42$)$ & most likely $\downarrow$ \\
\hline Training exposure (min) & $16891 \pm 1151$ & $18987 \pm 1829$ & $14795 \pm 474$ & $-2.63(-3.20$ to -2.06$)$ & most likely $\downarrow$ \\
\hline
\end{tabular}

Data are mean \pm standard deviation for each group.

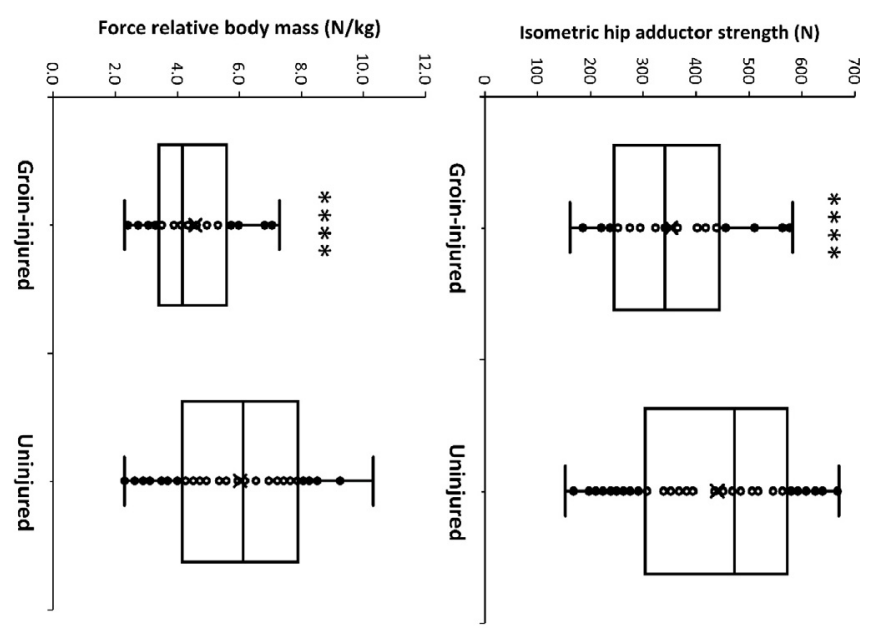

Fig. 2. Box-and-whisker plots for maximal isometric hip adductor strength (upper panel) and force relative to body mass (lower panel) in football players who suffered a groin injury or remained uninjured in this location during the competitive season. The lower, middle and upper lines of the box represent the 25, 50 and $75 \%$ percentile for each group. Whiskers represent lowest and highest values (range). ${ }^{* * * *}$ denotes a very large effect size between groups.

suffer a groin injury of $83 \%$.

The distribution of groin injuries over the entire season was not equal. As observed in Fig. 3 a higher percentage (44\%) of groin injuries were reported during the first two months, (i.e., the preseason and the first month of the competitive season) and January $(22.2 \%)$ in while no groin-injuries were reported in December and in the last two months of the season.

\section{Discussion}

The aim of this study was to analyse the association between hip adductor strength, assessed with the adductor squeeze test, and groin injury incidence during a competitive season in elite football players. The main findings of the present study showed that football players who suffered a groin injury during the season had lower values of hip adductor strength, in absolute and relative to body mass terms, than their uninjured players. This information suggests that the measurement of hip adductor strength in elite football players might be a good tool to estimate the likelihood of suffering an overuse groin injury during the season. In addition, the investigation suggests that those players with low values of hip adductor strength should be engaged in specific training programs aimed to prevent overuse groin injuries.

According to the present findings, football players who sustained groin injuries during the competitive period showed weaker isometric adductor strength at the beginning of the season. These outcomes contrast with those recently obtained by Mosler et al. (2018b), who reported no association between bilateral isometric hip adduction strength, using the squeeze test, and the risk of groin injuries in professional football players. The different outcomes between investigations might be linked to the characteristics of the two cohorts under investigation. While the sample of professional football players in Mosler's investigation had values for body mass of $\sim 72 \mathrm{~kg}$ and for body height of $\sim 177 \mathrm{~cm}$, the mean values of the professional players of this investigation were $80 \mathrm{~kg}$ and $182 \mathrm{~cm}$, respectively. In fact, the characteristics of the football players in Mosler's investigation were comparable with our U19 squad (body mass $\sim 71 \mathrm{~kg}$ and height $\sim 176 \mathrm{~cm}$ ). Moreover, training and playing exposure were rather different between the two cohorts: Mosler et al. (2018b) reported an average of $209 \mathrm{~h}$ of training and $25 \mathrm{~h}$ of match play while the uninjured group in the current investigation was exposed to $\sim 316 \mathrm{~h}$ of training and $\sim 66 \mathrm{~h}$ of match play. All this information, taken together, suggests that the players investigated the present study might be considered with a higher football level, in terms of both physicality (i.e., body mass and height) and training/playing exposure, than the ones investigated by Mosler et al. (2018b).

The contrasting findings, regarding the role of adductor strength in the risk of groin injuries in football players, is not a new issue in the literature on this topic. For example, Engebretsen et al. (2010) reported that adductor muscle weakness was associated with a 4fold increase in risk of groin injury in players with otherwise normal strength values. On the contrary, having higher than normal eccentric adduction strength was associated with an increased risk of groin injuries (Mosler et al., 2018b). This overall lack of consensus between the role of adductor strength and the risk of groin injuries in football players might be related with the various potential mechanisms of the different categories of groin injuries and the differences in level and exposure of the samples studied (Mosler et al., 2018b). Further research with football players to elucidate the most appropriate tests to assess adductor strength and the potential risk of the different groin injuries is warranted. However, the present investigation adds to the literature important information to consider the assessment of hip adductor strength in the pre-season to discriminate those players with higher risk of overuse groin injuries.

Table 2

Results from binary logistic regression of maximal isometric adductor strength and force relative to body mass comparing groin-injured and uninjured football players.

\begin{tabular}{|c|c|c|c|c|c|c|c|c|}
\hline & B & S.E. & Wald & df & Sig. & $\operatorname{Exp}(B)$ & $95 \% \mathrm{CI}$ & \\
\hline Maximal isometric adductor strength & .005 & .002 & 5.387 & 1 & .020 & 1.005 & 1.001 & 1.009 \\
\hline Force relative to body mass & 1.917 & .471 & 16.536 & 1 & .000 & 6.800 & 2.699 & 17.129 \\
\hline
\end{tabular}

Abbreviations: $\mathrm{B}=$ changes probabilities; S.E. = Standart error; Wald = Wald test; $\mathrm{df}-$ degrees of freedom; Sig $=$ satistical significance; Exp(B) = Odds ratio. 


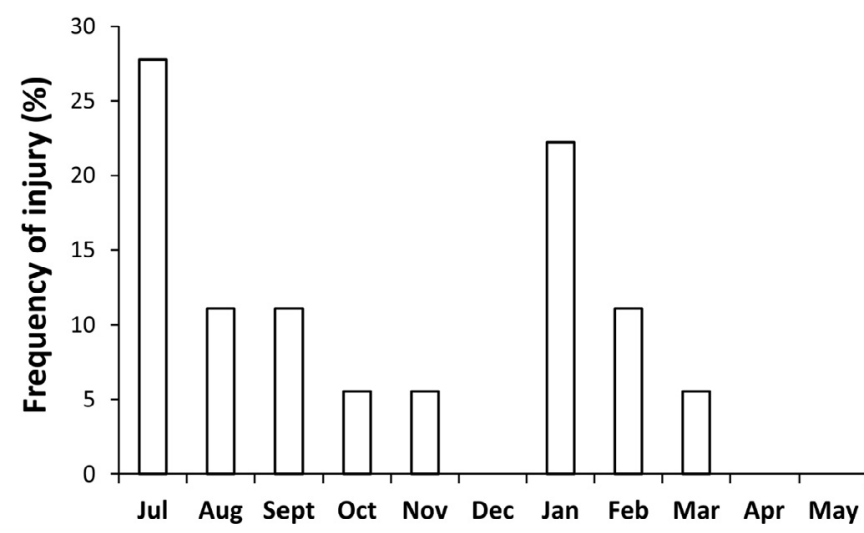

Fig. 3. Frequency of groin injuries in football players during the competitive season.

In the current analysis, the force relative to body mass showed a greater magnitude effect than absolute values of isometric hip adductor strength when comparing injured and uninjured players. Specifically, the results of the analysis of force relative to body mass revealed that a decrease in $1 \mathrm{~N} / \mathrm{kg}$ increased the chance to suffer a groin injury in 6.8 times. Furthermore, values of force relative to body mass lowert han $6.971 \mathrm{~N} / \mathrm{kg}$ increased the probability to suffer a groin injury in $83 \%$. Regarding maximal isometric adductor strength in absolute terms, the results revealed that a decrease in $1 \mathrm{~N}$ increased the chance to suffer a groin injury in $1 \%$. Also, values of maximal isometric adductor strength lower than $465.33 \mathrm{~N}$ increased the probability to suffer a groin injury in $72 \%$. According to other researchers (Kloskowska, Morrissey, Small, Malliaras, \& Barton, 2016), factors such as strength and muscle activation may clearly depend on the individual athlete's fitness and muscle morphology and could explain the best values obtained in force relative to body mass. These results of are in agreement with the results obtained in previous studies conducted with athletes of other sports that also entail repeated sudden changes of direction and/or repetitive kicking actions such as Australian and Gaelic football players (Crow et al., 2010; Delahunt, Fitzpatrick, \& Blake, 2017) also assessed with the isometric adductor squeeze test. Specifically, in a prospective cohort study on 113 Australian football players Crow et al. (2010) found that hip adductor muscle strength was decreased by $5.83 \%$ the week that preceded or the actual week of the onset of a groin injury in elite under-age Australian footballers. Furthermore, Delahunt et al. (2017) reported that in 55 male elite Gaelic football players a pre-season test score below $225 \mathrm{mmHg}$ (as determined by the use of a sphygmomanometer recording during the adductor squeeze test) predicted a groin injury with a sensitivity of 0.70 and a specificity of 0.78 . Based on the above data, force relative to body mass could be considered as an interesting individual measurement that increases the sensitivity to detect strength deficits related with groin pain in football players.

The current study showed that a $7 \%$ and $13.5 \%$ of all injuries that occurred during the first season and second season, respectively, were groin injuries. Furthermore, match-related groin injuries occurred more frequently than training-related groin injuries (5.2; $95 \%$ CI 3.82 to 6.80 ). These findings are similar to previous football epidemiological studies that show a similar percentage $(4 \%-21 \%)$ of groin injuries in professional football players per season (Hägglund et al., 2009; Mosler et al., 2018b; Noya, Gómez-Carmona, GraciaMarco, Moliner-Urdiales, \& Sillero-Quintana, 2014; Werner et al., 2009) and reported higher percentage of injuries during matches 3.5 per $1000 \mathrm{~h}(95 \% \mathrm{Cl}, 2.7-4.3)$ than training, with 0.7 per $1000 \mathrm{~h}$ (95\% CI, 0.6-0.8 (Mosler et al., 2018b);).
Another interesting finding of the present study was the groin injury distribution during the season (Fig. 3). The present data showed that the majority of groin injuries were reported to occur in July and August (38.8\%) (i.e., pre-season) and January (22.2\%), while the lowest number of groin injuries was reported in November and December (5.5\%). These results are in line with previous reports with professional male football players (Woods et al., 2004). A previous study (Walden, Hagglund, Orchard, Kristenson, \& Ekstrand, 2013) found regional differences in injury incidence in European professional football due to differences in tactics, playing style, playing intensity, and climate-related differences in ground hardness. In Portugal, professional soccer players start the preseason and season at the end of July and August, respectively. Thus, the highest incidence of groin injuries in those months might be related by the excessive and/or inappropriate accumulation of training load and associated lack of recovery during the pre-season period. Therefore, based on the present results, an extra care could be placed during the preseason with those players with relatively weaker adductors.

While the results of this study have provided information regarding the relationship between the isometric adductor hip strength and force relative to body mass in pre-season using the adductor squeeze test and the incidence of suffering groin injury over season in professional football players, limitations to the study must be acknowledged. Firstly, as the current study has been performed in a specific sample of football players, these findings may not be extended to another athletes' population. Additionally, other potential weakness is that the current information is related to the beginning of the season (pre-season screening programme) and do not provide information on how these scores may vary during the season or from season to season. We have calculated cutoff point to determine the likelihood of suffering a groin injury, in both absolute and relative terms, but these thresholds should be used with caution because they might vary in terms intra and interindividual variability of the measurement and/or with the use of other models of handheld dynamometers. Finally, we set a 3-month exclusion criterion from any previous groin/hip injury in our study sample while the strength deficit produced by a previous groin/hip injury might last more than this established period. Despite these limitations, the authors believe that the manuscript adds valuable information to provide an easy and useful screening test to increase the likelihood of preventing groin injuries in football players.

\section{Conclusion}

The results of the present study revealed a significantly lower isometric adductor strength, and strength relative to body mass, in groin-injured elite football players during a competition season. The measurement of normalized force values in relation to body mass (force relative to body mass) for each player seems to constitute an interesting individual variable that might help to identify the risk of groin injuries in football players.

\section{Acknowledgements}

We would like to thank the players for their uninterested participation in this study.

\section{References}

Arnason, A., Sigurdsson, S. B., Gudmundsson, A., Holme, I., Engebretsen, L., \& Bahr, R. (2004). Risk factors for injuries in football. The American Journal of Sports Medicine, 32(1Suppl), 5S-16S.

Bakken, A., Targett, S., Bere, T., Eirale, C., Farooq, A., Mosler, A. B., et al. (2018) Muscle strength is a poor screening test for predicting lower extremity injuries in professional male soccer players: A 2-year prospective cohort study. The 
American Journal of Sports Medicine, 46, 1481-1491.

Cejudo, A., Sainz de Baranda, P., Ayala, F. \& Santonja, F. (2015). Test-retest reliability of seven common clinical tests for assessing lower extremity muscle flexibility in futsal and handball players. Physical Therapy in Sport, 16, 107-112.

Coughlan, G. F., Delahunt, E., Caulfield, B. M., Forde, C., \& Green, B. S. (2014). Normative adductor squeeze test values in elite junior rugby union players. Clinical Journal of Sport Medicine, 24, 315-319.

Crow, J. F., Pearce, A. J., Veale, J. P., VanderWesthuizen, D., Coburn, P. T., \& Pizzari, T. (2010). Hip adductor muscle strength is reduced preceding and during the onset of groin pain in elite junior Australian football players. Journal of Science and Medicine in Sport, 13, 202-204.

Delahunt, E., Fitzpatrick, H., \& Blake, C. (2017). Pre-season adductor squeeze test and HAGOS function sport and recreation subscale scores predict groin injury in Gaelic football players. Physical Therapy in Sport, 23, 1-6.

Delahunt, E., Kennelly, C., McEntee, B. L., Coughlan, G. F., \& Green, B. S. (2011). The thigh adductor squeeze test: 45 of hip flexion as the optimal test position for eliciting adductor muscle activity and maximum pressure values. Manual Therapy, 16, 476-480.

Dvorak, J., Junge, A., Grimm, K., \& Kirkendall, D. (2007). Medical report from the 2006 FIFA World cup Germany. British Journal of Sports Medicine, 41, 578-581.

Ekstrand, J., Hägglund, M., \& Waldén, M. (2011). Injury incidence and injury patterns in professional football: The UEFA injury study. British Journal of Sports Medicine, 45, 553-558.

Emery, C. A., \& Meeuwisse, W. H. (2001). Risk factors for groin injuries in hockey. Medicine \& Science in Sports \& Exercise, 33, 1423-1433.

Engebretsen, A. H., Myklebust, G., Holme, I., Engebretsen, L., \& Bahr, R. (2010). Intrinsic risk factors for groin injuries among male soccer players: A prospective cohort study. The American Journal of Sports Medicine, 38, 2051-2057.

Esteve, E., Rathleff, M. S., Vicens-Bordas, J., Clausen, M. B., Holmich, P., Sala, L., et al. (2018). Preseason adductor squeeze strength in 303 Spanish male soccer athletes: A cross-sectional study. Orthopaedic Journal Sports Medicine, 6 , 2325967117747275.

Fuller, C. W., Ekstrand, J., Junge, A., Andersen, T. E., Bahr, R., Dvorak, J., et al. (2006) Consensus statement on injury definitions and data collection procedures in studies of football (soccer) injuries. British Journal of Sports Medicine, 40, 193-201.

Hägglund, M., Waldén, M., \& Ekstrand, J. (2009). Injuries among male and female elite football players. Scandinavian Journal of Medicine \& Science in Sports, 19, $819-827$.

Hanna, C. M., Fulcher, M. L., Elley, C. R., \& Moyes, S. A. (2010). Normative values of hip strength in adult male association football players assessed by handheld dynamometry. Journal of Science and Medicine in Sport, 13, 299-303.

Herrero, H., Salinero, J. J., \& Del Coso, J. (2014). Injuries among Spanish male amateur soccer players: A retrospective population study. The American Journal of Sports Medicine, 42, 78-85.

Hölmich, P., Thorborg, K., Dehlendorff, C., Krogsgaard, K., \& Gluud, C. (2014). Incidence and clinical presentation of groin injuries in sub-elite male soccer. British Journal of Sports Medicine, 48, 1245-1250.

Hopkins, W. G., Marshall, S. W., Batterham, A. M., \& Hanin, J. (2009). Progressive statistics for studies in sports medicine and exercise science. Medicine \& Science in Sports \& Exercise, 41, 3-13.

Ibrahim, A., Murrell, G. A., \& Knapman, P. (2007). Adductor strain and hip range of movement in male professional soccer players. Journal of Orthopaedic Surgery, $15,46-49$.

Kloskowska, P., Morrissey, D., Small, C., Malliaras, P., \& Barton, C. (2016). Movement patterns and muscular function before and after onset of sports-related groin pain: A systematic review with meta-analysis. Sports Medicine, 46, 1847-1867.

Machotka, Z., Kumar, S., \& Perraton, L. G. (2009). A systematic review of the literature on the effectiveness of exercise therapy for groin pain in athletes. Sports Medicine, Arthroscopy, Rehabilitation, Therapy, Technology, 31, 5.

Mesquita, R., Gonçalves, B., Tavares, F., Brito, J., Correia, P., Santos, P., et al. (2018). Maximal strength and rate of force development of hip adduction and abduction: Reliability of measures from a portable dynamometer. In Paper presented at the international congress of strength training, Perth, Western Australia. https:// icst2018.com/cms/wp-content/uploads/ICST-2018-Abstract-Book.pdf.
Mohammad, W. S., Abdelraouf, O. R., Elhafez, S. M., Abdel-Aziem, A. A., \& Nassif, N. S. (2014). Isokinetic imbalance of hip muscles in soccer players with osteitis pubis. Journal of Sports Sciences, 32, 934-939.

Moreno-Pérez, V., Lopez-Valenciano, A., Barbado, D., Moreside, J., Elvira, J., \& VeraGarcia, F. (2017). Comparisons of hip strength and countermovement jump height in elite tennis players with and without acute history of groin injuries. Musculoskeletal Science \& Practice, 29, 144-149.

Mosler, A. B., Crossley, K. M., Thorborg, K., Whiteley, R. J., Weir, A., Serner, A., et al. (2017). Hip strength and range of motion: Normal values from a professional football league. Journal of Science and Medicine in Sport, 20, 339-343.

Mosler, A. B., Weir, A., Eirale, C., Farooq, A., Thorborg, K., Whiteley, R. J., et al. (2018a). Epidemiology of time loss groin injuries in a men's professional football league: A 2-year prospective study of 17 clubs and 606 players. British Journal of Sports Medicine, 52, 292-297.

Mosler, A. B., Weir, A., Serner, A., Agricola, R., Eirale, C., Farooq, A., et al. (2018b). Musculoskeletal screening tests and bony hip morphology cannot identify male professional soccer players at risk of groin injuries: A 2-year prospective cohort study. The American Journal of Sports Medicine, 46, 1294-1305.

Murphy, J. C., Gissane, C., \& Blake, C. (2012). Injury in elite county-level hurling: A prospective study. British Journal of Sports Medicine, 46, 138-142.

Murphy, J. C., O’Malley, E., Gissane, C., \& Blake, C. (2012). Incidence of injury in Gaelic football: A 4-year prospective study. The American Journal of Sports Medicine, 40, 2113-2120.

Noya Salces, J., Gómez-Carmona, P. M., Gracia-Marco, L., Moliner-Urdiales, D., \& Sillero-Quintana, M. (2014). Epidemiology of injuries in first division Spanish football. Journal of Sports Sciences, 32, 1263-1270.

O'Connor, D. (2004). Groin injuries in professional rugby league players: A prospective study. Journal of Sports Sciences, 22, 629-636.

Roe, G. A., Phibbs, P. J., Till, K., Jones, B. L., Read, D. B., Weakley, J. J., et al. (2016). Changes in adductor strength after competition in academy rugby union players. The Journal of Strength \& Conditioning Research, 30, 344-350.

Ryan, J., DeBurca, N., \& Mc Creesh, K. (2014). Risk factors for groin/hip injuries in field-based sports: A systematic review. British Journal of Sports Medicine, 48, 1089-1096.

Swets, J. A. (1988). Measuring the accuracy of diagnostic systems. Science, 240, 1285-1293.

Tak, I., Glasgow, P., Langhout, R., Weir, A., Kerkhoffs, G., \& Agricola, R. (2016). Hip range of motion is lower in professional soccer players with hip and groin symptoms or previous injuries, independent of cam deformities. The American Journal of Sports Medicine, 44, 682-688.

Thorborg, K., Serner, A., Petersen, J., Madsen, T. M., Magnusson, P., \& Holmich, P. (2011). Hip adduction and abduction strength profiles in elite soccer players: Implications for clinical evaluation of hip adductor muscle recovery after injury. The American Journal of Sports Medicine, 39, 121-126.

Tyler, T. F., Nicholas, S. J., Campbell, R. J., \& McHugh, M. P. (2001). The association of hip strength and flexibility with the incidence of adductor muscle strains in professional ice hockey players. The American Journal of Sports Medicine, 29, 124-128.

Waldén, M., Hägglund, M., \& Ekstrand, J. (2005). UEFA champions league study: A prospective study of injuries in professional football during the 2001-2002 season. British Journal of Sports Medicine, 39, 542-546.

Walden, M., Hagglund, M., Orchard, J., Kristenson, K., \& Ekstrand, J. (2013). Regional differences in injury incidence in European professional football. Scandinavian Journal of Medicine \& Science in Sports, 23, 424-430.

Werner, J., Hagglund, M., Walden, M., \& Ekstrand, J. (2009). UEFA injury study: A prospective study of hip and groin injuries in professional football over seven consecutive seasons. British Journal of Sports Medicine, 43, 1036-1040.

Whittaker, J. L., Small, C., Maffey, L., \& Emery, C. A. (2015). Risk factors for groin injury in sport: An updated systematic review. British Journal of Sports Medicine, 49, 803-809. https://doi.org/10.1136/bjsports-2014-094287.

Woods, C., Hawkins, R., Maltby, S., Hulse, M., Thomas, A., \& Hodson, A. (2004). The football association medical research programme: An audit of injuries in professional football-analysis of hamstring injuries. British Journal of Sports Medicine, 38, 36-41. 